\title{
Comparing mortality and myocardial infarction between coronary artery bypass grafting and drug- eluting stenting in patients with diabetes mellitus and multivessel coronary artery disease: a meta-analysis
}

\author{
Xiaolong $\mathrm{Qi}^{1}$, Mingxin $\mathrm{Xu}^{1}$, Haitao Yang ${ }^{2}$, Lin Zhou ${ }^{3}$, Yu Mao ${ }^{3}$, Haoming Song ${ }^{3}$, Quan $\mathrm{Li}^{4}$, \\ Changqing Yang ${ }^{1}$
}

\author{
${ }^{1}$ Institute of Digestive Disease, Tongji Hospital, Tongji University School of Medicine, \\ Shanghai, China \\ 2Division of Cardiology, Henan Provincial People's Hospital, Zhengzhou, China \\ ${ }^{3}$ Division of Cardiology, Tongji Hospital, Tongji University School of Medicine, \\ Shanghai, China \\ ${ }^{4}$ Division of Anesthesiology, Shanghai Tenth People's Hospital, Tongji University \\ School of Medicine, Shanghai, China
}

Submitted: 12 October 2013

Accepted: 23 December 2013

Arch Med Sci $2014 ; 10,3: 411-418$

DOI: 10.5114 /aoms.2014.43734

Copyright @ 2014 Termedia \& Banach

\begin{abstract}
Introduction: We aim to compare the midterm outcomes between coronary artery bypass grafting (CABG) and percutaneous coronary intervention ( $\mathrm{PCI}$ ) in diabetic patients who had multivessel coronary artery diseases (CAD).

Material and methods: A comprehensive literature search was conducted to identify the related clinical studies with a follow-up for 1 year at least. The endpoints were death, myocardial infarction, and major adverse cardiac and cerebrovascular events (MACCE).

Results: Finally, the analysis of ten studies involving 5,264 patients showed that patients with CABG had worse baseline characteristics, a higher rate of stable angina pectoris, a higher percentage of triple-vessel disease, higher incidence of chronic total occlusion and a higher SYNTAX score. However, there was no significant difference in mortality between the two groups. Additionally, the rates of myocardial infarction and MACCE were markedly decreased in the CABG group.

Conclusions: The strategy of CABG is better than $\mathrm{PCl}$ for diabetic patients with multivessel CAD. The CABG can significantly reduce the rates of myocardial infarction and MACCE and is comparable in mortality despite the worse baseline characteristics.
\end{abstract}

Key words: coronary artery bypass grafting, percutaneous coronary intervention, coronary artery diseases.

\section{Introduction}

Diabetic patients experience a higher risk of coronary artery disease (CAD) and are more likely to develop more severe symptoms than non-diabetics [1, 2]. It is reported that there are more than 220 million people with diabetes worldwide and the number is expected to rise to 360 million by 2030 [3]. About one fifth of patients with unstable angina or nonST evaluated myocardial infarction have diabetes mellitus, which is associated with advanced CAD, accounting for a higher rate of myocardial infarction and mortality [4-6]. As the leading cause of mortality among

\author{
Corresponding author: \\ Prof. Changqing Yang \\ Tongji Hospital \\ Tongji University School \\ of Medicine \\ 389 Xin Cun Road \\ 200065 Shanghai, China \\ Phone: +86-21-66111076 \\ E-mail: \\ changqingyang@126.com, \\ cqyang@tongji.edu.cn
}


diabetic patients, cardiovascular disease accounts for up to $80 \%$ of diabetes-related deaths $[7,8]$.

A clinical trial showed that there was lower mortality and repeat revascularization in diabetic patients treated with coronary artery bypass grafting (CABG) than percutaneous coronary intervention (PCI) [9]. However, drug-eluting stenting (DES) has been recently demonstrated to reduce in-stent restenosis and repeat revascularization compared to bare-metal stenting in diabetic patients. Thus, in the DES era, the optimal revascularization strategy for diabetic patients with multivessel CAD remains unknown [10-12]. We performed a meta-analysis to compare the efficacy of CABG and DES in diabetic patients with multivessel CAD.

\section{Material and methods}

\section{Data sources}

We searched Medline, EMBASE, metaRegister of Controlled Trials, and Cochrane databases from January 2003 to July 2013 for clinical studies, using the Medical Subject Heading terms "coronary artery bypass graft surgery", "drug-eluting stent", "diabetes mellitus" and "multivessel coronary artery disease". The Science Citation Index was used to cross-reference studies that met the inclusion criteria.

\section{Study selection}

Studies were selected on the basis of pre-determined criteria: a clinical trial was included if it: (1) was published in journals with the full text in English, (2) compared the use of DES to CABG in diabetic patients with multivessel CAD $(\geq 2$ arteries), (3) had a follow-up $\geq 12$ months. Studies using bare-metal stenting and describing the same article were excluded. The end points were death, myocardial infarction and major adverse cardiac and cerebrovascular events (MACCE). The MACCE was defined as a composite of all-cause death, cerebrovascular accident, myocardial infarction or repeat revascularization (any subsequent $\mathrm{PCl}$ or CABG procedure in any coronary vessel).

\section{Data abstraction}

We captured pre-specified data elements for each study, including baseline characteristics and clinic outcomes. Data extraction from text, tables, and figures was performed by 2 independent reviewers. Decisions were compared and a consensus was reached. Discrepancies were resolved through discussion.

\section{Statistical analysis}

The meta-analysis was conducted with Review Manager 5.2. Forest plots and funnel plots were generated for graphical presentations, and Q statistics were computed to assess heterogeneity across the different studies. We used a fixed-effects model of meta-analysis to aggregate data; however, the randomized-effects model was used when effects were heterogeneous $\left(R^{2}>50 \%\right)$. The summary risk differences and odds ratios (OR) comparing CABG and DES outcomes and the $95 \% \mathrm{Cl}$ for each result were computed.

\section{Results}

\section{Eligible studies}

Ten studies ( 2 randomized trials and 8 nonrandomized trials) were included in the meta-analysis and their baseline characteristics are presented in Table I [12-21]. There was an absence of baseline characteristics of the Banning et al. study, because the baseline patient demographics and lesion characteristics in CABG and DES groups were shown as a composite outcome for the diabetic cohort [18]. The rest of the initial citations were excluded based on the titles/ abstracts, language, publication type, etc. A total of 5,264 patients were included in the analysis (2,585 CABG and 2,679 DES patients). In most studies, sirolimus-eluting and paclitaxel-eluting stents were provided to the patients in the $\mathrm{PCl}$ procedure. However, in the studies of Onuma et al. [14] and Yamagata et al. [15], PCI was performed by implantation of only sirolimus-eluting stents, whereas only paclitaxel-eluting stents were used in the study of Banning et al. [18]. The CABG was performed without elective extracorporeal circulation including a left internal mammary artery for revascularization of the left anterior descending coronary artery whenever possible in most cases. The mean follow-up duration was 3.2 years.

\section{Study characteristics}

The CABG group had higher percentages of stable angina pectoris (OR 1.32, 95\% Cl: 1.06-1.64) (Figure 1), triple-vessel disease (OR 4.59, 95\% Cl: 2.08-10.11) (Figure 2), chronic total occlusion (OR 1.94, 95\% Cl: 1.29-2.92) (Figure 3) and SYNTAX scores (mean difference $5.73,95 \% \mathrm{Cl}: 1.67-9.78$ ) (Figure 4). There is no other significant difference in baseline characteristics between the CABG group and DES group.

\section{Clinical outcomes}

We also performed a subgroup analysis comparing $\mathrm{PCl}$ with $\mathrm{DES}$ vs. CABG. Among non-randomized studies, OR was comparable between the DES group and the CABG group for the endpoints, with the exception of MACCE rate. There was a significantly higher risk for MACCE in patients treated with 


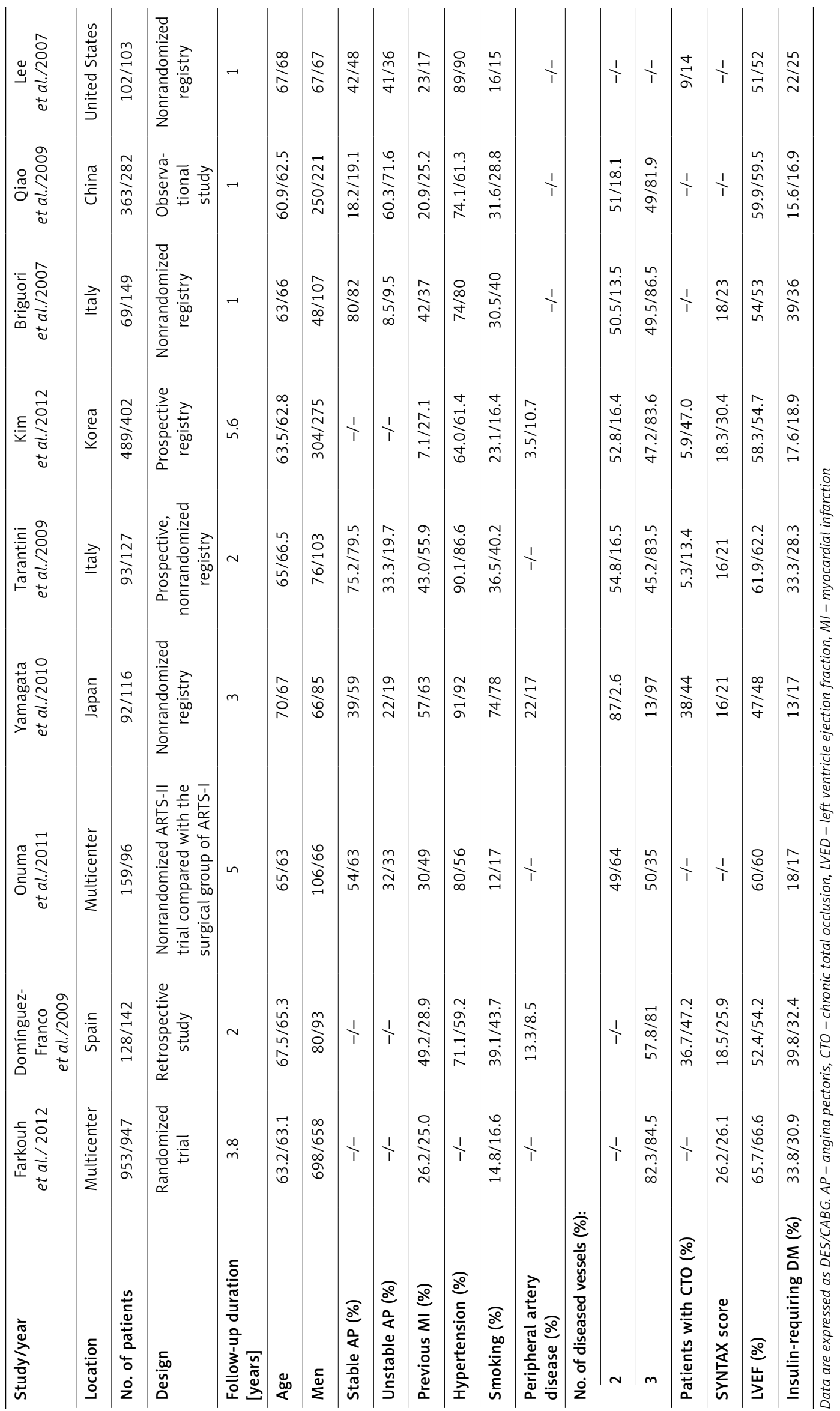




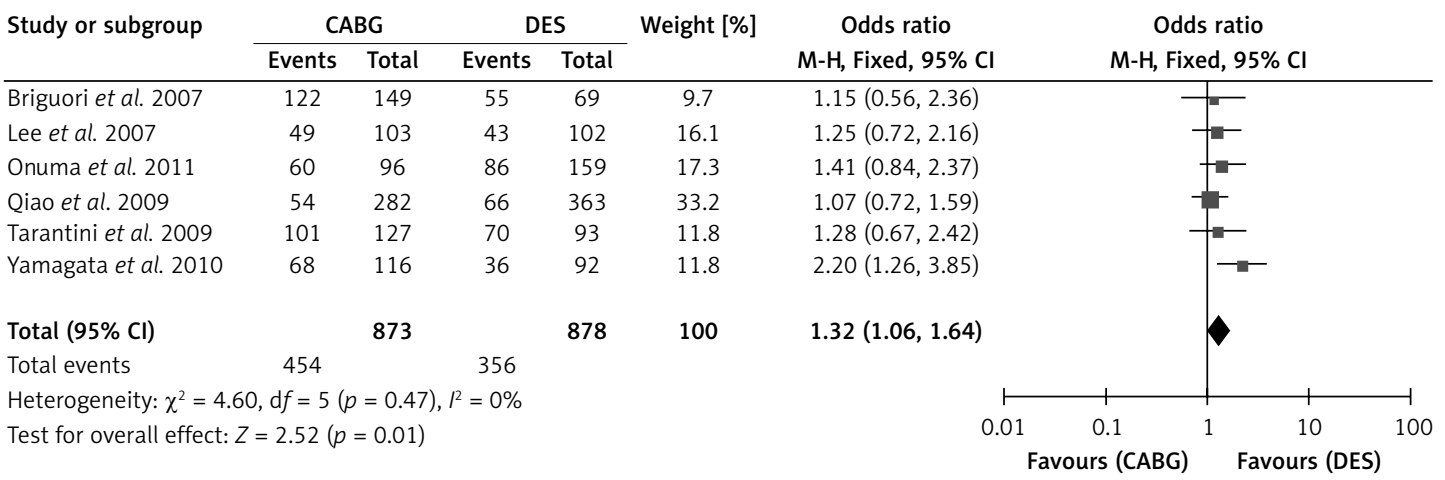

Figure 1. Odds ratio and conclusions plot of stable angina pectoris

\begin{tabular}{|c|c|c|c|c|c|c|c|c|c|}
\hline \multirow[t]{2}{*}{ Study or subgroup } & \multicolumn{2}{|c|}{ CABG } & \multicolumn{2}{|c|}{ DES } & \multirow{2}{*}{$\begin{array}{l}\text { Weight } \\
{[\%]}\end{array}$} & \multirow{2}{*}{$\begin{array}{l}\text { Odds ratio } \\
\mathrm{M}-\mathrm{H}, \text { Random, } 95 \% \mathrm{Cl}\end{array}$} & \multirow{2}{*}{\multicolumn{2}{|c|}{$\begin{array}{l}\text { Odds ratio } \\
\mathrm{M}-\mathrm{H} \text {, Random, } 95 \% \mathrm{Cl}\end{array}$}} & \\
\hline & Events & Total & Events & Total & & & & & \\
\hline Briguori et al. 2007 & 129 & 149 & 34 & 69 & 12.3 & $6.64(3.41,12.93)$ & & - - & \\
\hline Dominguez et al. 2009 & 115 & 142 & 74 & 128 & 12.7 & $3.11(1.80,5.37)$ & & & \\
\hline Farkouh et al. 2012 & 793 & 939 & 780 & 948 & 13.4 & $1.17(0.92,1.49)$ & & 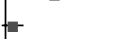 & \\
\hline Kim et al. 2012 & 336 & 402 & 231 & 489 & 13.2 & $5.69(4.14,7.82)$ & & - & \\
\hline Onuma et al. 2011 & 33 & 96 & 80 & 159 & 12.8 & $0.52(0.31,0.87)$ & -- & & \\
\hline Qiao et al. 2009 & 231 & 282 & 178 & 363 & 13.2 & $4.71(3.26,6.79)$ & & - & \\
\hline Tarantini et al. 2009 & 106 & 127 & 42 & 93 & 12.5 & $6.13(3.29,11.41)$ & & $\multimap-$ & \\
\hline Yamagata et al. 2010 & 113 & 116 & 12 & 92 & 9.9 & $251.11(68.63,918.79)$ & & & \\
\hline Total $(95 \% \mathrm{Cl})$ & & 2253 & & 2341 & 100 & $4.59(2.08,10.11)$ & & & \\
\hline Total events & 1856 & & 1431 & & & & & & \\
\hline \multicolumn{7}{|c|}{$\begin{array}{l}\text { Heterogeneity: } \tau^{2}=1.20, \chi^{2}=175.48, \mathrm{~d} f=7(p<0.00001), I^{2}=96 \% \\
\text { Test for overall effect: } Z=3.78(p=0.0002)\end{array}$} & $\frac{1}{0.1}$ & 1 & 100 \\
\hline \multicolumn{7}{|c|}{ Test for overall effect: $Z=3.78(p=0.0002)$} & Favours (CABG) & Favours & \\
\hline
\end{tabular}

Figure 2. Odds ratio and conclusions plot of triple-vessel disease

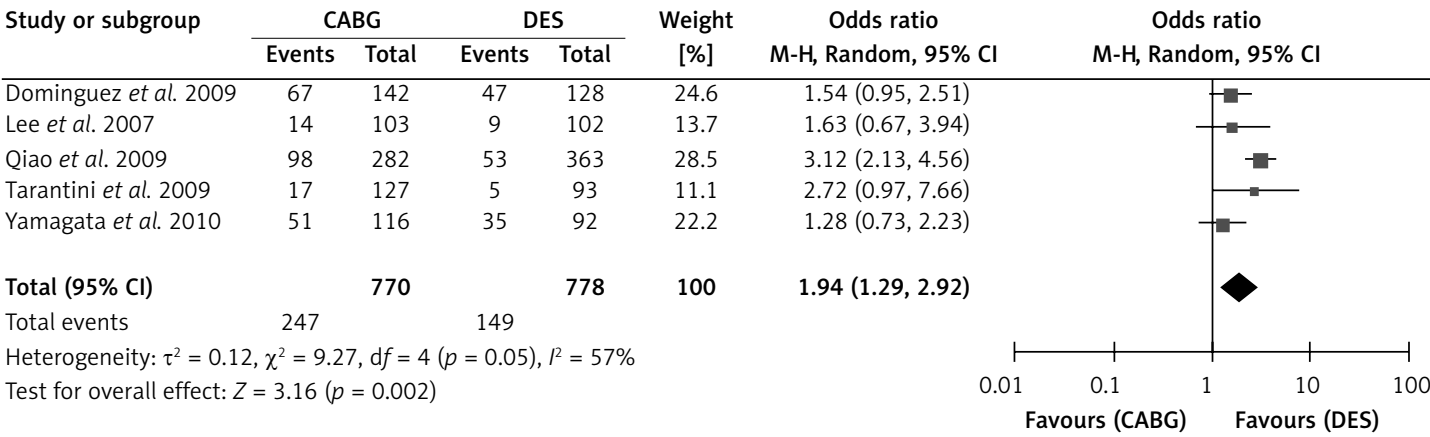

Figure 3. Odds ratio and conclusions plot of chronic total occlusion

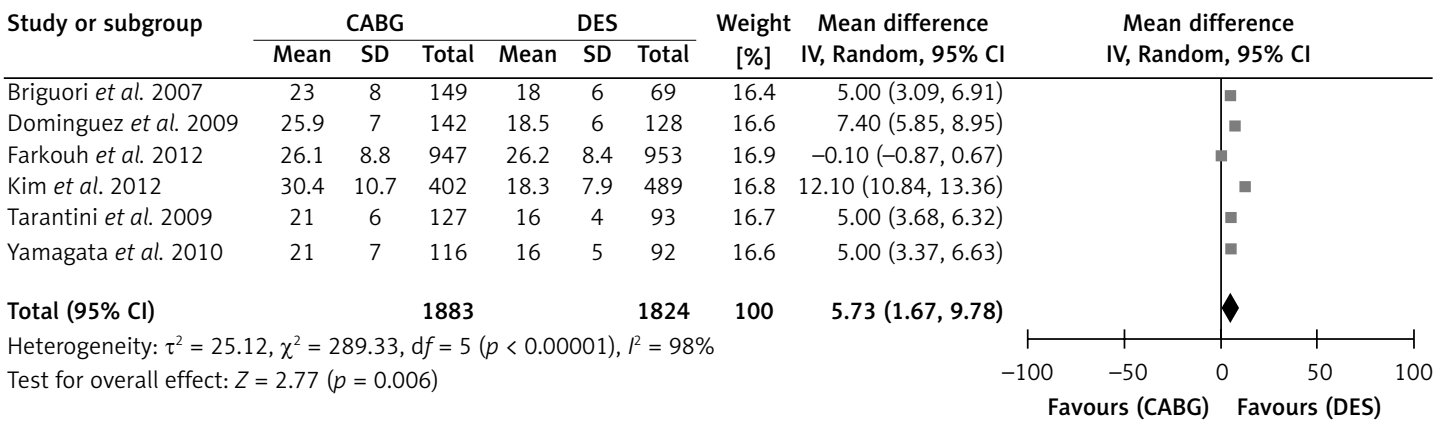

Figure 4. Mean difference and conclusions plot of SYNTAX scores 
DES compared with CABG (OR 0.60, 95\% Cl: 0.500.72). However, DES was associated with significantly increased risks for all three endpoints in the randomized studies. Generally, the OR for mortality was 0.89 , indicating that CABG was associated with lower mortality compared with DES, though the effect did not reach statistical significance between the two revascularizations (Figure $5 \mathrm{~A}$ ). The $\chi^{2}$ test with 9 degrees of freedom for the $\mathrm{Q}$ statistic was $7.14\left(p=0.62, P^{2}=0 \%\right)$, indicating no significant heterogeneity among the studies. However, there was a statistically significant difference in MACCE rate: CABG could dramatically reduce the rate of MACCE (OR 0.60, 95\% Cl: 0.52-0.69) (Figure $6 \mathrm{~A}$ ). There was no significant heterogeneity among the studies as the $\chi^{2}$ test with 9 degrees of freedom for the $\mathrm{Q}$ statistic was $9.29\left(p=0.41, R^{2}=3 \%\right)$. Additionally, a sig- nificant difference in myocardial infarction between the two groups was revealed (Figure $7 \mathrm{~A}$ ). The OR for myocardial infarction was $0.57(95 \% \mathrm{Cl}$ : 0.44-0.75), indicating that CABG was associated with lower incidence of myocardial infarction compared with DES. The $\chi^{2}$ test with 8 degrees of freedom for the $\mathrm{Q}$ statistic was $9.28\left(p=0.32, P^{2}=14 \%\right)$, indicating no significant heterogeneity among the studies. In addition, the funnel plot for each endpoint was shown (Figures 5 B, 6 B and 7 B).

\section{Discussion}

In clinical practice, most patients are treated with $\mathrm{PCl}$ for single-vessel disease and with $\mathrm{CABG}$ for severe CAD, such as triple-vessel or severe left main disease [22]. Due to the lack of random al-

A

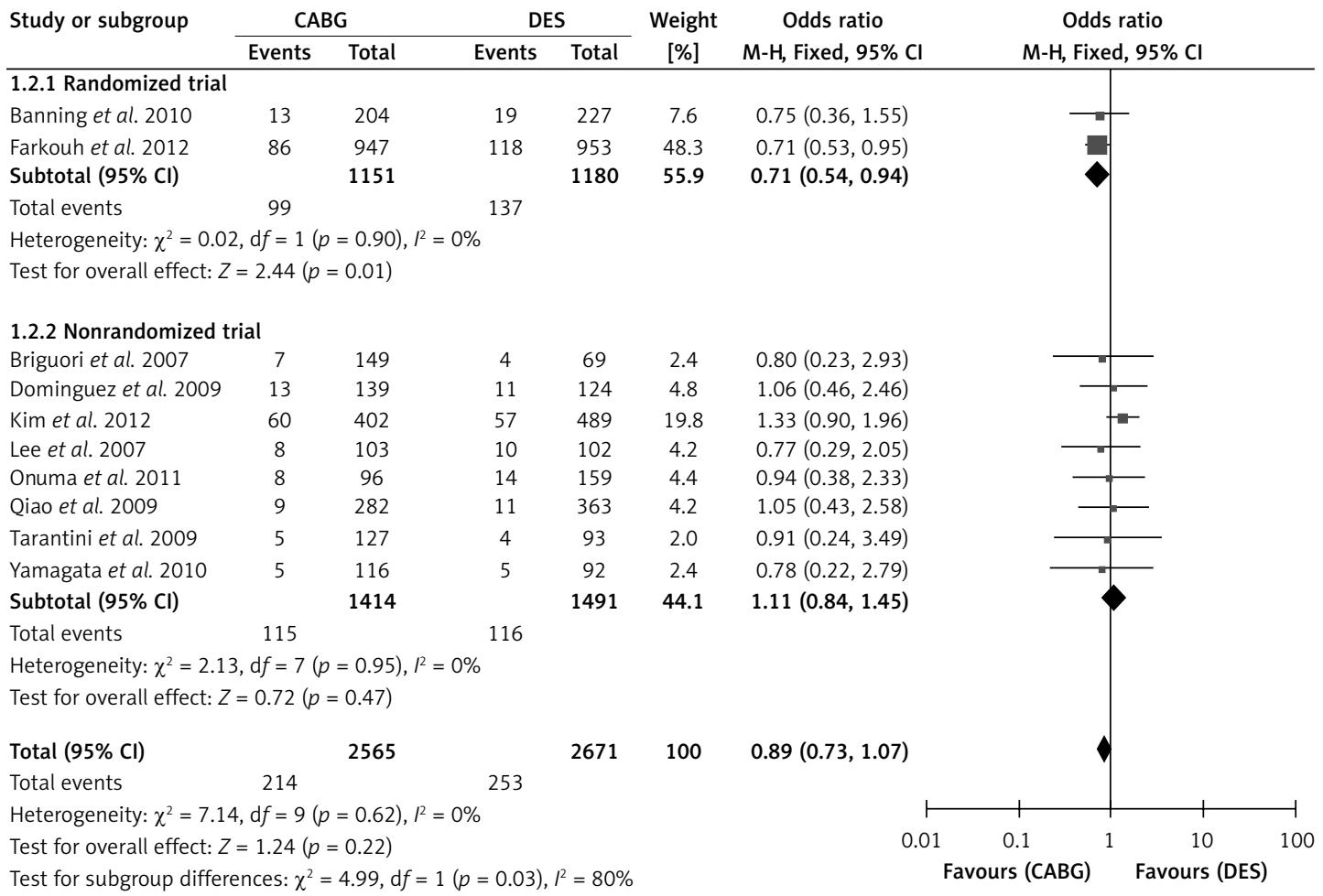

B

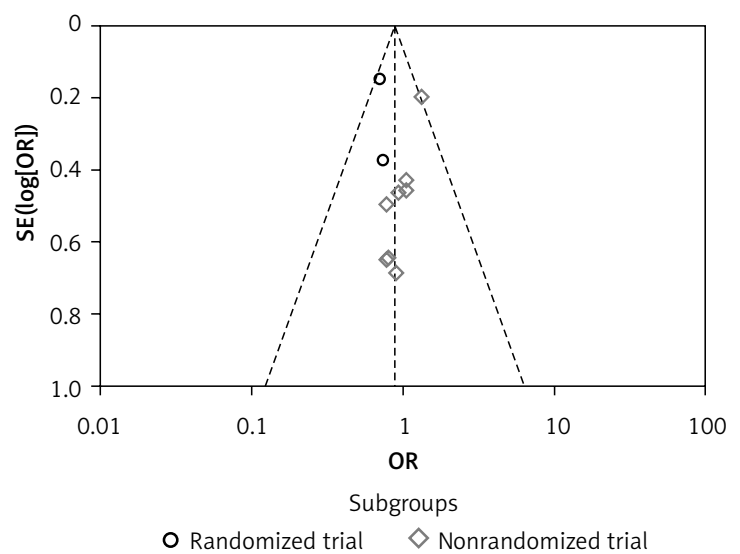

Figure 5. Forest plot (A) and funnel plot (B) of mortality 
A

\begin{tabular}{|c|c|c|c|c|c|c|c|c|c|}
\hline \multirow[t]{2}{*}{ Study or subgroup } & \multicolumn{2}{|c|}{ CABG } & \multicolumn{2}{|c|}{ DES } & \multirow{2}{*}{$\begin{array}{l}\text { Weight } \\
{[\%]}\end{array}$} & \multirow{2}{*}{$\begin{array}{c}\text { Odds ratio } \\
\mathrm{M}-\mathrm{H}, \text { Fixed, } 95 \% \mathrm{Cl}\end{array}$} & \multirow{2}{*}{\multicolumn{2}{|c|}{$\begin{array}{c}\text { Odds ratio } \\
\text { M-H, Fixed, } 95 \% \mathrm{Cl}\end{array}$}} & \\
\hline & Events & Total & Events & Total & & & & & \\
\hline \multicolumn{10}{|l|}{ 1.1.1 Randomized trial } \\
\hline Banning et al. 2010 & 29 & 204 & 59 & 227 & 9.8 & $0.47(0.29,0.77)$ & $\rightarrow-$ & & \\
\hline Farkouh et al. 2012 & 106 & 947 & 157 & 953 & 28.4 & $0.64(0.49,0.83)$ & $=$ & & \\
\hline Subtotal $(95 \% \mathrm{Cl})$ & & 1151 & & 1180 & 38.2 & $0.60(0.47,0.75)$ & $>$ & & \\
\hline Total events & 135 & & 216 & & & & & & \\
\hline \multicolumn{10}{|c|}{ Heterogeneity: $\chi^{2}=1.13, \mathrm{~d} f=1(p=0.29), I^{2}=12 \%$} \\
\hline \multicolumn{10}{|c|}{ Test for overall effect: $Z=4.35(p<0.0001)$} \\
\hline \multicolumn{10}{|c|}{ 1.1.2 Nonrandomized trial } \\
\hline Briguori et al. 2007 & 29 & 149 & 20 & 69 & 4.5 & $0.59(0.31,1.14)$ & $\longrightarrow$ & & \\
\hline Dominguez et al. 2009 & 26 & 139 & 27 & 124 & 4.7 & $0.83(0.45,1.51)$ & $\longrightarrow$ & & \\
\hline Kim et al. 2012 & 98 & 402 & 163 & 489 & 22.7 & $0.64(0.48,0.87)$ & - & & \\
\hline Lee et al. 2007 & 16 & 103 & 28 & 102 & 4.9 & $0.49(0.24,0.97)$ & & & \\
\hline Onuma et al. 2011 & 22 & 96 & 63 & 159 & 7.5 & $0.45(0.26,0.80)$ & $\longrightarrow-$ & & \\
\hline Qiao et al. 2009 & 22 & 282 & 65 & 363 & 10.7 & $0.39(0.23,0.65)$ & -- & & \\
\hline Tarantini et al. 2009 & 17 & 127 & 12 & 93 & 2.5 & $1.04(0.47,2.30)$ & - & & \\
\hline Yamagata et al. 2010 & 27 & 116 & 25 & 92 & 4.4 & $0.81(0.43,1.53)$ & 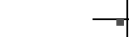 & & \\
\hline Subtotal $(95 \% \mathrm{Cl})$ & & 1414 & & 1491 & 61.8 & $0.60(0.50,0.72)$ & $\boldsymbol{\gamma}$ & & \\
\hline Total events & 257 & & 403 & & & & & & \\
\hline \multicolumn{10}{|c|}{ Heterogeneity: $\chi^{2}=8.15, \mathrm{~d} f=7(p=0.32), I^{2}=14 \%$} \\
\hline \multicolumn{10}{|c|}{ Test for overall effect: $Z=5.46(p<0.00001)$} \\
\hline Total $(95 \% \mathrm{Cl})$ & & 2565 & & 2671 & 100 & $0.60(0.52,0.69)$ & 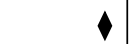 & & \\
\hline Total events & 392 & & 619 & & & & & & \\
\hline \multicolumn{6}{|c|}{ Heterogeneity: $\chi^{2}=9.29, \mathrm{~d} f=9(p=0.41), I^{2}=3 \%$} & $\longmapsto$ & 1 & & -1 \\
\hline \multicolumn{6}{|c|}{ Test for overall effect: $Z=6.98(p<0.00001)$} & 0.01 & $0.1 \quad 1$ & $1 \quad 10$ & 100 \\
\hline \multicolumn{10}{|c|}{ Test for subgroup differences: $\chi^{2}=0.00, \mathrm{~d} f=1(p=0.94), l^{2}=0 \% \quad$ Favours (CABG) $\quad$ Favours (DES) } \\
\hline
\end{tabular}

B

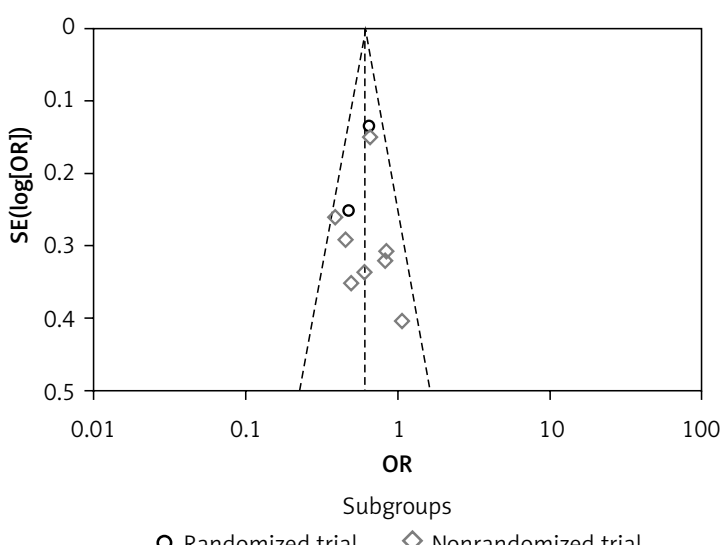

Figure 6. Forest plot (A) and funnel plot (B) of MACCE rate

location, patients in observational studies tend to present a large bias. As a result, patients with focal disease are more likely to undergo $\mathrm{PCl}$ and those with extensive $C A D$ are likely to undergo CABG. The strategy of revascularization is driven by angiographic data, such as extent, location and nature of the lesion.

A meta-analysis by Lee et al. showed that there was no significant difference in death and myocardial infarction between the CABG group and the DES group when the mean follow-up was 18 months (range 12 to 36), which led to the conclusion that $\mathrm{PCl}$ with DES was safe and might represent a viable alternative to CABG for patients with diabetes and multivessel CAD [10]. However, in the FREEDOM trial by Farkouh et al., 1,900 patients with diabetes and multivessel CAD at 140 centers were enrolled and randomly assigned to undergo either $\mathrm{PCI}$ with DES or CABG. The primary outcome measure was a composite of death from any cause, nonfatal myocardial infarction, and nonfatal stroke. They demonstrated that CABG was superior to $\mathrm{PCl}$ for diabetic patients with advanced $C A D$ considering the mortality and myocardial infarction [12]. Accordingly, the optimal revascularization strategy for diabetic patients with multivessel CAD remains uncertain.

In our meta-analysis, we conducted a comparison of baseline characteristics between the $\mathrm{PCl}$ group and the CABG group. Patients in the CABG group had worse characteristics before being treated, with a higher percentage of stable angina pectoris, triple-vessel disease and chronic total occlusion, and higher SYNTAX scores. Although 
A

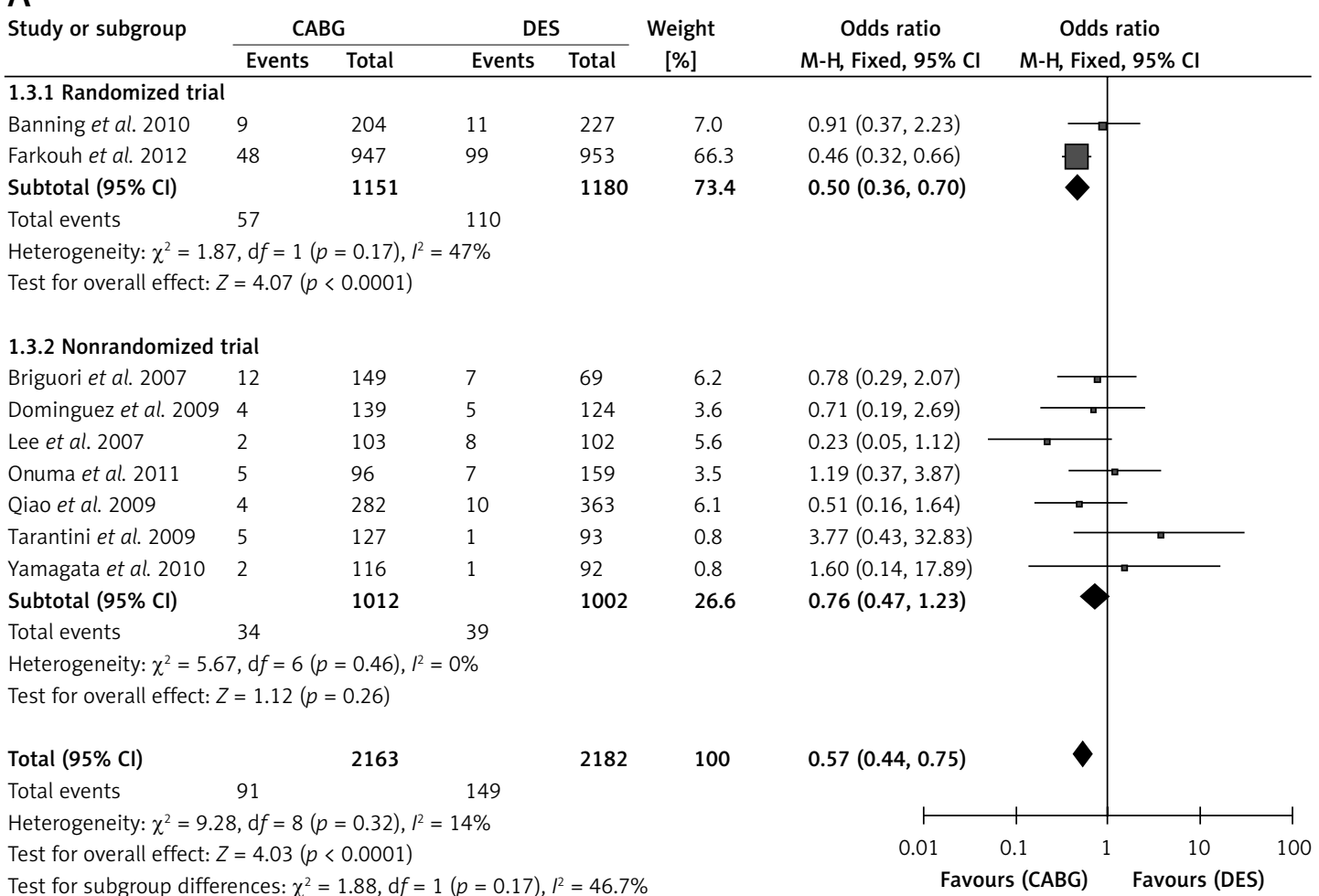

B

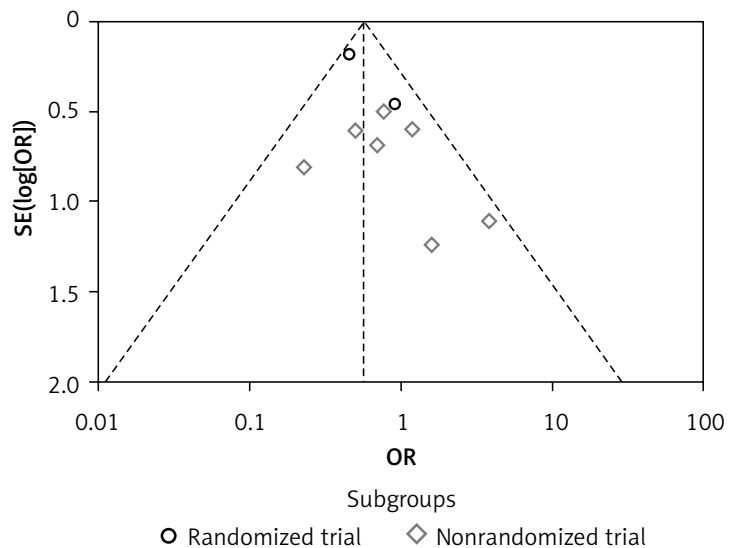

Figure 7. Forest plot (A) and funnel plot (B) of myocardial infarction

the mortality was similar in the two groups, the CABG strategy showed superiority for diabetic patients because of the lower rate of myocardial infarction, MACCE and worse baseline characteristics. Therefore, our study, like the FREEDOM trial, further confirmed that CABG had better midterm outcomes than DES.

The major difference between our study and the meta-analysis by Lee et al. was the duration of follow-up. The mean follow-up period of the Lee et al. meta-analysis was 18 months vs. 3.2 years in ours. Besides, recently published data comparing $\mathrm{PCl}$ and $\mathrm{CABG}$ were also updated and included in our analysis. In the Lee et al. analysis, 5 observational studies (a total of 1543 patients) from January 2003 to July 2009 were included [14, 16, 19-21], while five more studies including 3721 participants published recently were included in our meta-analysis [12, 13, 15, 17, 18], 2 of which were randomized trials. Moreover, the results of clinical outcomes showed an obvious discrepancy between our analysis and that of Lee et al., as noted above.

The 2011 ACCF/AHA guideline showed that CABG (especially with one or both internal mammary arteries) led to more complete revascularization and a decreased need for additional procedures when compared with $\mathrm{PCl}$ [23]. Due to the diffuse nature of diabetic $C A D$, the relative benefits of CABG over PCI may well persist for patients even in the era of DES. The study is not without limitations. First, this meta-analysis adopted the published event rates instead of specific individual data for each trial. Second, there were limited 
clinical trials included in the analysis and the numbers of patients in each cohort were small. Finally, some results of endpoints were not available, such as data of myocardial infarction in the study by Kim et al. [17].

In conclusion, the meta-analysis suggested that the strategy of CABG is better than PCI with DES for diabetic patients with multivessel CAD. In spite of the worse baseline characteristics, the CABG approach could significantly reduce the rate of myocardial infarction and major adverse cardiac cerebrovascular events, while obtaining a similar mortality when compared with $\mathrm{PCl}$.

\section{Acknowledgments}

Xiaolong Qi, Mingxin Xu, Haitao Yang - equal contributors. We appreciate the great contributions of Dr. Haitao Yang for the constructive comments and previous carefully revision. Therefore, we all agree to accept Dr. Haitao Yang as a co-first author of the manuscript.

This study was supported by the National Natural Science Foundation of China (81070343); Shanghai Science and Technology Innovation Action Plan (12431901002).

\section{References}

1. Kereiakes DJ, Cutlip DE, Applegate RJ, et al. Outcomes in diabetic and nondiabetic patients treated with everolimus or paclitaxel-eluting stents:results from the SPIRIT IV clinical trial (Clinical Evaluation of the XIENCE V Everolimus Eluting Coronary Stent System). J Am Coll Cardiol 2010; 56: 2084-9.

2. Haffner SM, Lehto S, Rönnemaa T, et al. Mortality from coronary heart disease in subjects with type 2 diabetes and in nondiabetic subjects with and without prior myocardial infarction. N Engl J Med 1998; 339: 229-34.

3. Wild S, Roglic G, Green A, et al. Global prevalence of diabetes: estimates for the year 2000 and projections for 2030. Diabetes Care 2004; 27: 1047-53.

4. Bravata DM, Gienger AL, MCDonald KM, et al. Systematic review: the comparative effectiveness of percutaneous coronary interventions and coronary artery bypass graft surgery. Ann Intern Med 2007; 147: 703-16.

5. Jacoby RM, Nesto RW. Acute myocardial infarction in the diabetic patient: pathophysiology, clinical course and prognosis. J Am Coll Cardiol 1992; 20: 736-44.

6. Kip KE, Faxon DP, Detre KM, et al. Coronary angioplasty in diabetic patients. The national heart, lung, and blood institute percutaneous transluminal coronary angioplasty registry. Circulation 1996; 94: 1818-25.

7. Kannel WB, McGee DL. Diabetes and cardiovascular disease: the Framingham study. JAMA 1979; 241: 2035-8.

8. Harris MI. Diabetes in American: epidemiology and scope of the problem. Diabetes Care 1998; 21: C11-4.

9. The BARI Investigators. The final 10-year follow-up results from the BARI randomized trial. J Am Coll Cardiol 2007; 49: 1600-6.

10. Lee MS, Yang T, Dhoot J, et al. Meta-analysis of studies comparing coronary artery bypass grafting with drug-eluting stenting in patients with diabetes mellitus and multivessel coronary artery disease. Am J Cardiol 2010; 105: 1540-4.

11. Athyros VG, Gossios TD, Tziomalos K, et al. Is there an additional benefit from coronary revascularization in diabetic patients with acute coronary syndromes or stable angina who are already on optimal medical treatment? Arch Med Sci 2011; 7: 1067-75.

12. Farkouh ME, Domanski M, Sleeper LA, et al. Strategies for multivessel revascularization in patients with diabetes. N Engl J Med 2012; 367: 2375-84.

13. Domínguez-Franco AJ, Jiménez-Navarro MF, HernándezGarcía JM, et al. Comparison of medium-term outcomes obtained with drug-eluting stents and coronary artery bypass grafts in an unselected population of diabetic patients with multivessel coronary disease. Propensity score analysis. Rev Esp Cardiol 2009; 62: 491-500.

14. Onuma Y, Wykrzykowska JJ, Garg S, et al. 5-Year follow-up of coronary revascularization in diabetic patients with multivessel coronary artery disease: insights from ARTS (arterial revascularization therapy study)-II and ARTS-I trials. JACC Cardiovasc Interv 2011; 4: 317-23.

15. Yamagata K, Kataoka Y, Kokubu N, et al. A 3-Year clinical outcome after percutaneous coronary intervention using sirolimus-eluting stent and off-pump coronary artery bypass grafting for the treatment of diabetic patients with multivessel disease. Circ J 2010; 74: 671-8.

16. Tarantini G, Ramondo A, Napodano $\mathrm{M}$, et al. PCl versus CABG for multivessel coronary disease in diabetics. Catheter Cardiovasc Interv 2009; 73: 50-8.

17. Kim YG, Park DW, Lee WS, et al. Influence of diabetes mellitus on long-term (five-year) outcomes of drug-eluting stents and coronary artery bypass grafting for multivessel coronary revascularization. Am J Cardiol 2012; 109: 1548-57.

18. Banning AP, Westaby S, Morice MC, et al. Diabetic and nondiabetic patients with left main and/or 3-vessel coronary artery disease: comparison of outcomes with cardiac surgery and paclitaxel-eluting stents. J Am Coll Cardiol 2010; 55: 1067-75.

19. Briguori C, Condorelli G, Airoldi F, et al. Comparison of coronary drug-eluting stents versus coronary artery bypass grafting in patients with diabetes mellitus. Am J Cardiol 2007; 99: 779-84.

20. Lee MS, Jamal F, Kedia G, et al. Comparison of bypass surgery with drug-eluting stents for diabetic patients with multivessel disease. Int I Cardiol 2007; 123: 34-42.

21. Qiao Y, Ma C, Nie S, et al. Twelve months clinical outcome of drug-eluting stents implantation or coronary artery bypass surgery for the treatment of diabetic patients with multivessel disease. Clin Cardiol 2009; 32: e24-30.

22. Brener SJ, Lytle BW, Casserly IP, et al. Predictors of revascularization method and long-term outcome of percutaneous coronary intervention or repeat coronary bypass surgery in patients with multivessel coronary disease and previous coronary bypass surgery. Eur Heart J 2006; 27: 413-8.

23. Wright RS, Anderson JL, Adams CD, et al. 2011 ACCF/ AHA focused update incorporated into the ACC/AHA 2007 guidelines for the management of patients with unstable angina/non-ST elevation myocardial infarction: a report of the American College of Cardiology Foundation/American Heart Association Task Force on practice guidelines developed in collaboration with the American Academy of Family Physicians, Society for Cardiovascular Angiography and Interventions, and the Society of Thoracic Surgeons. J Am Coll Cardiol 2011; 57: e215-367. 